\title{
Exergy analysis of cavitation pretreatment of sludge
}

\author{
Stawomir Różycki ${ }^{1, *}$, and Marian Banaś ${ }^{1}$ \\ ${ }^{1}$ AGH University of Science and Technology, Department of Power Systems and Environmental \\ Protection Facilities, 30-059 Kraków Al. Mickiewicza 30, Poland
}

\begin{abstract}
A number of papers present exergy analyses of various wastewater treatment systems. The current development of these systems is mainly aimed at improving their energy efficiency, reducing the share of sludge subject to storage, and reducing their harmfulness. Some of these systems can be supported by the use of the cavitation phenomenon in the processing. The generation of cavitation requires, however, the use of devices or machines and thus additional energy consumption. Therefore, this treatment should be objectively justified, e.g. through exergy analysis, which takes into account not only the amount of energy used in processes, but also its quality. The paper treats the methodology for determining the impact of the use of cavitation in the exergy balance of sewage sludge treatment system. Then, it presents the results of an exemplary analysis comparing sewage sludge treatment systems (with and without application of cavitation phenomenon) in which biogas is produced during the fermentation, then burned in a co-generator, finally receiving useful energy in the form of electric current and hot flue gas stream.
\end{abstract}

\section{Introduction}

Depending on the amount and composition of sewage, as well as the target quality parameters of water that may be discharged into the environment, wastewater treatment plants use various technological systems, consisting of many machines and devices [1]. We usually divide them into systems responsible for:

- mechanical treatment (gratings, grit chambers, preliminary settling tanks),

- biological treatment (biological reactors, secondary settling tanks),

- treatment of sewage sludge (thickeners, digesters, incinerators).

The paramount objective of the processes carried out in wastewater treatment plants is to minimize the hazards that wastewater could cause in the environment. These hazards arise from dangerous, often toxic, contaminants, that after cleaning the water are found in sewage sludge [2]. For this reason, the sludge must be pre-processed prior to utilization (e.g. in agriculture or land reclamation). However, standard biological methods do not always allow to obtain sludge parameters allowing for their natural use, due to the increasing content of heavy metals, organic pollutants (PAH, PCBs, AOX) and the presence of pathogenic organisms and parasitic eggs [3]. Therefore, more and more often sewage

* Corresponding author: srozycki@agh.edu.pl 
treatment plants use advanced mechanical, thermal, or chemical pretreatment of sludge, and in plans for sewage sludge management, a growing share of sludge treated with thermal methods with energy recovery is predicted [4]. Energy recovery from sludge, characterized by relatively high heating value, has become one of the priorities of modern sewage sludge management [5].

The recovery of energy included in organic pollutants contained in sewage sludge is possible, among others through the production of biogas in the anaerobic digestion process, based on the biological decomposition of organic substances under the influence of anaerobic bacteria. The biogas obtained in the digestion process normally consists of $60-70 \%$ methane, $30-35 \%$ carbon dioxide, $1-2 \%$ hydrogen sulfide and $0.3-3 \%$ nitrogen [6]. From the obtained biogas, it is possible to produce electricity and useful heat in a combined heat and power (CHP) plant.

The article treats an exergy analysis of this part of the wastewater treatment plant, which is directly responsible for the energetic use of sewage sludge through its digestion. The aim of the presented analysis is to determine the impact of the use of an additional process of disintegration of sewage sludge, using the phenomenon of cavitation, on the exergy efficiency of sewage treatment plants, with the purpose of providing guidance for the scale-up application of wastewater treatment system with cavitation pretreatment of sludge in the future. This additional process, although generates additional energy demand, is increasingly used due to the multiple benefits of its use [7], [8]:

- $20 \%$ greater yield of biogas from the anaerobic digestion process,

- fewer solid residues, i.e. reduced amount of sludge that needs to be disposed,

- greater susceptibility to dewatering,

- degradation of organic compounds (dyes, surfactants, halides, aromatic compounds, polycyclic aromatic hydrocarbons).

Although exergy performance assessments of the waste water treatment plants have been widely considered [6], [9]-[18], exergy analysis of the treatment of sewage sludge with cavitation pretreatment is also greatly required, as the methods based on hydrodynamic cavitation are currently being intensively developed [2], [8], [19]-[23]. Despite the fact that the presented results are valid only for assumed data, the methodology described in this article may also be used for real data from industrial plants to show the exergetic potential of their modification.

\section{Methods}

The development of technological systems used in wastewater treatment plants includes replacing machines and processes characterized by significant energy losses, by the ones that achieve the same effect with less energy consumption. Yet, the concept of energy consumption is inaccurate because energy can be processed, but its quantity in accordance with the first law of thermodynamics remains unchanged. However, Each irreversible process causes a change in the "quality of energy", which can be expressed using the exergy parameter, that is based on both the first and the second law of thermodynamics. Therefore, this parameter, although slightly more difficult to interpret than the energy parameter, is more adequate to compare processes, machines and even entire technologies as it takes into account not only the amount of processed energy, but also the amount of degraded energy. 


\subsection{The use of exergy approach in the assessment of the efficiency of wastewater utilization}

To determine the exergy, we need a reference point expressed as the reference value of the environment in which the system is located. The practical energy usefulness of matter becomes zero if this matter is reduced to a thermodynamic equilibrium with the surrounding natural environment. Since the real natural environment is a very complex system, for practical reasons, there must be assumed the idealized natural environment that is in a state of thermodynamic equilibrium with the surrounding nature [24].

The quality of individual systems can be related, for example, to the share of individual carbon compounds in these systems. The compound which has almost zero exergy will be carbon dioxide at $25^{\circ} \mathrm{C}$, under partial pressure of $0.0335 \mathrm{kPa}$ due to the general access to this compound and its limited use. In turn, coal, hydrocarbons, carbohydrates, etc. have a higher exergy, as they can be used to produce useful energy, primarily mechanical and electrical energy [25]. The large differences between standard values of chemical exergy of different substances are presented in the Table 1 . Some of these values were used in the analysis discussed in this article.

Table 1. Standard Chemical Exergy of Selected Substances at $101.325 \mathrm{kPa}$ and $298.15 \mathrm{~K}$ (based on [26]).

\begin{tabular}{|l|c|c|c|c|}
\hline \multicolumn{1}{|c|}{ Substance } & State & Formula & $\mathbf{e}^{\text {ch }}[\mathbf{k J} / \mathbf{m o l}]$ & $\mathbf{e}^{\text {ch }}[\mathbf{k J} / \mathbf{g}]$ \\
\hline Hydrogen & gas & $\mathrm{H}_{2}$ & 236.1 & 117.11 \\
\hline Oxygen & gas & $\mathrm{O}_{2}$ & 4.0 & 0.13 \\
\hline Coal & solid graphite & $\mathrm{C}$ & 410.3 & 34.16 \\
\hline Carbon monoxide & gas & $\mathrm{CO}$ & 275.1 & 9.82 \\
\hline Carbon dioxide & gas & $\mathrm{CO}_{2}$ & 19.9 & 0.45 \\
\hline Water & liquid & $\mathrm{H}_{2} \mathrm{O}$ & 0.9 & 0.05 \\
\hline Water & gas & $\mathrm{H}_{2} \mathrm{O}$ & 9.5 & 0.53 \\
\hline Methane & gas & $\mathrm{CH}_{4}$ & 831.7 & 51.84 \\
\hline n-Octane & liquid & $\mathrm{C}_{8} \mathrm{H}_{18}$ & 5413.1 & 47.39 \\
\hline Ethanol & liquid & $\mathrm{C}_{2} \mathrm{H}_{5} \mathrm{OH}$ & 1357.7 & 29.47 \\
\hline
\end{tabular}

\subsection{Exergy analysis of sewage sludge processing}

Exergy analysis may consist in the execution of an exergy balance, on the basis of which it is possible to determine in which parts of the technological process the losses of exergy due to thermodynamic irreversibility of processes are the largest and on the basis of which we can conclude about the potential of reducing these losses. In the exergy analysis, apart from the exergy balance, we also often use the parameter of the exergy efficiency of the entire system and subsystems, as well as the relative irreversibility of individual processes.

The analyzed system is an open system under steady-state conditions. It consists of anaerobic digesters (AD), combined heat and power plant (CHP) and, optionally, a cavitation generator (PT) - Fig. 1. The cavitation generator serves here for the pretreatment of sewage sludge by disintegration of their cellular structure. 


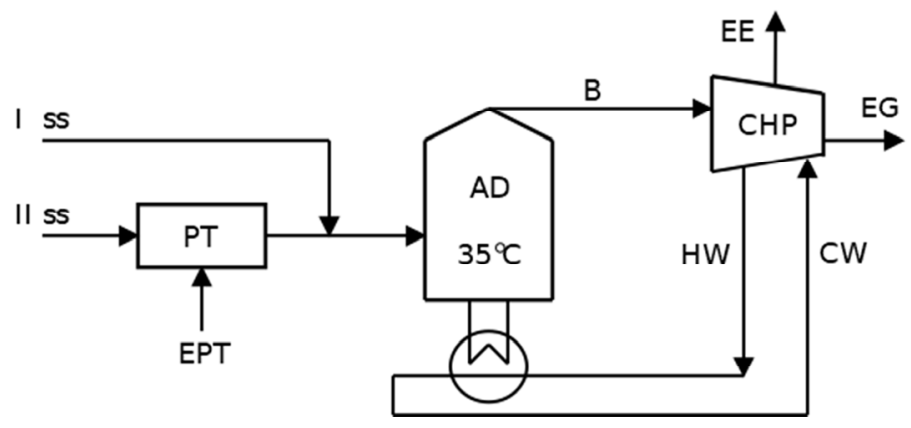

Fig. 1. Energy recovery from sewage sludge with an anearobic digestion process and CHP system (based on [21]) : I, II - $1^{\text {st }}$ and $2^{\text {nd }}$ variant of analyzied system, respectively; ss - raw sewage sludge; PT - pretreatment process; AD - anearobic digestion tank; CHP - combined heat and power plant; EPT - energy for PT; B - biogas stream; EE - electrical energy; EG - energy of exhaust gases; HW - hot water; CW - cold water.

For the purposes of the analysis, it was assumed that the wastewater treatment plant capacity is $150,000 \mathrm{~m}^{3} /$ day with a total suspended solids concentration of $286.1 \mathrm{mg} / \mathrm{dm}^{3}$ [27]. It was also assumed that the sludge concentration is $150 \mathrm{~g} / \mathrm{dm}^{3}$, and anaerobic digestion efficiency is $45 \%$ [21]. The sewage sludge properties assumed for analyses were based on the results of the research presented by Karki [14] (Table 2).

The next assumptions concern the efficiency of combined heat and power (CHP) plant. The following values were adopted for calculations of exergy [21]:

- total efficiency of $\mathrm{CHP}$ plant: $85 \%\left(\mathrm{E}_{\mathrm{B}}\right.$ - biogas energy; $0.15 \mathrm{E}_{\mathrm{B}}$ - loss of energy contained in biogas)

- electricity generation: $0.35 \times\left(0.85 \mathrm{E}_{\mathrm{B}}\right)$

- energy in the form of useful exhaust gases at a temperature of $400^{\circ} \mathrm{C}: 0.30 \times\left(0.85 \mathrm{E}_{\mathrm{B}}\right)$

- energy in the form of hot water (for the purpose of heating of anaerobic digestion tanks):0.35 x $\left(0.85 \mathrm{E}_{\mathrm{B}}\right)$.

The biogas desulphurisation process, which often occurs before the application of biogas in a gas engine of CHP plant, was not included in the studies due to its potentially minor impact on the results of the analysis.

Table 2. Properties of raw sewage sludge [14].

\begin{tabular}{|c|c|c|}
\hline \multirow{4}{*}{ Elemental Analysis (wt \%)* } & $\mathrm{C}$ & 37.82 \\
\cline { 2 - 3 } & $\mathrm{H}$ & 5.82 \\
\cline { 2 - 3 } & $\mathrm{N}$ & 4.14 \\
\cline { 2 - 3 } & $\mathrm{O}$ & 25.12 \\
\cline { 2 - 3 } & $\mathrm{S}$ & 1.44 \\
\cline { 2 - 3 } Proximate Analysis (wt \%)** & Others & 25.66 \\
\cline { 2 - 3 } & Moisture & 80.12 \\
\cline { 2 - 3 } & Volatile Content & 12.87 \\
\cline { 2 - 3 } & Ash & 5.50 \\
\hline \multirow{2}{*}{ HHV (MJ/kg)* } & Fixed Carbon & 1.51 \\
\hline & & 15.81 \\
\hline
\end{tabular}

*Dry Basis; **Wet Basis; Others: inorganic components 
The exergy balance of the analyzed system is expressed by the equation:

$$
\sum_{\text {in }} \text { exergy }_{\imath}=\sum_{\text {out }} \text { exergy }_{e}+\dot{I}
$$

where: $\dot{I}$ - loss of exergy (irreversibility rate).

On the input side (in) of the variant I and II of the system (Fig. 1) there is an exergy of sewage sludge. In the case of variant II on the input side there is also an exergy brought into the system with the electric energy used for cavitation processing of raw sludge. On the output side (out) of the exergy balance equation, there is an exergy of products, i.e. the electricity and heat produced, and the loss of exergy caused by the lack of further use of the digested sludge, thermal losses and irreversibility of processes.

The considered system has two basic unit processes. As the internal loss of exergy in one process cannot be reduced in any way through other processes, the loss of exergy of entire system as the sum of exergy losses of individual unit processes may be considered [25]:

$$
\dot{I}_{\text {overall }}=\sum_{k} \dot{I}_{k}
$$

More or less complex subsystems as unit processes, depending on the required level of detail of exergy analysis might be considered.

The exergy efficiency of the system can be described by the formula:

$$
\eta_{\text {ex }}=\frac{\text { exergy in products }}{\text { total exergy input }}
$$

Exergy of sewage sludge stream, which enters into the system (exergy input), can be divided into kinetic exergy, potential exergy, physical exergy and chemical exergy. Due to the significant differences in the orders of magnitude of individual types of exergy, only the chemical exergy of sewage is of practical importance, therefore only this type of exergy has been included in the calculations.

\subsubsection{Chemical exergy of sewage sludge}

Sewage sludge is a heterogeneous mixture of various substances, therefore, the dependence suggested by Song [28], which is an averaging of measurements made for 86 biomass variants, whose chemical exergy on dry basis ranged from 11.5 to $24.2 \mathrm{MJ} / \mathrm{kg}$, was used to estimate its exergy. The ratio of the exergy to the higher heating value of different biomass species varied from 1.013 to 1.078 , thus assuming the average value, the following dependence on biomass chemical exergy was given by Song:

$$
E x_{d s}^{c h}=1.047 \cdot H H V_{d s}
$$

where: $\mathrm{HHV}_{\mathrm{ds}}$ - higher heating value, dry basis.

Although the Song's dependence (4) was determined for biomass, its use seems also valid for sewage sludge because, as has been shown by Griffth et al. [29] who measured the content of the ${ }^{14} \mathrm{C}$ isotope contained in sewage sludge, organic carbon of plant origin in sewage sludge constitutes from 75 to $86 \%$, and only the remaining part has a fossil origin. 
The approximate value of sewage sludge exergy can also be calculated based on the knowledge of their elemental composition. Hongliang et al. [30] delivered and verified a novel model for prediction of exergy of biomass, according to which we obtain sufficient accuracy by knowing only the content of such elements as carbon and hydrogen:

$$
E x_{d s}^{c h}=920.72\left(\frac{C}{3}+H\right)
$$

The water contained in the raw sludge can be included in its exergy according to the following dependence [25]:

$$
E x_{w s}^{c h}=z_{d s} \cdot E x_{d s}^{c h}+z_{\mathrm{H}_{2} \mathrm{O}} \cdot E x_{\mathrm{H}_{2} \mathrm{O}}^{c h}
$$

where: $z_{d s}, z_{\mathrm{H}_{2} \mathrm{O}}$ - percent fraction of dry substance and water,

$E x_{\mathrm{H}_{2} \mathrm{O}}^{c h}$ - exergy of water $(0,05 \mathrm{MJ} / \mathrm{kg})$.

\subsubsection{Exergy of biogas}

In the studied system, the first unit process is anaerobic digestion of sludge. Energy demand for heat and electricity of digestion tanks is met by an internal source (biogas-powered CHP plant - Fig. 1).

To calculate exergy of biogas we need to take into account all components it consists of. The chemical exergy of the gas mixture is smaller than the sum of the chemical exergies of the individual components mixed. Thus, exergy of biogas (gas mixture) is expressed by the following equation [25]:

$$
E x_{B}^{c h}=\sum_{i} x_{i} E x_{i}^{c h}+R T_{0} \sum_{i} x_{i} \ln \gamma_{i} x_{i}
$$

where: $E x_{i}^{c h}-$ molar specific chemical exergy of the $i^{\text {th }}$ substance,

$x_{i}$ - mole fraction of the $\mathrm{i}^{\text {th }}$ substance,

$\gamma_{i}$ - activity coefficient of the $i^{\text {th }}$ substance,

$\mathrm{R}$ - universal gas constant,

$\mathrm{T}_{0}$ - uniform environmental temperature.

Methane (the main component of biogas) usually constitutes $60-70 \%$. The volumetric flow of the produced methane can be expressed using the equation proposed by Cano et al. [21]:

$$
Q_{C_{4}}=0.34 \cdot c_{s l} \cdot \eta_{A D}
$$

where: $\eta_{A D}$ - anaerobic digestion efficiency,

$c_{s l}$ - sludge concentration.

\subsubsection{Exergy of useful products}

The second (and last) unit process of the studied system is the conversion of chemical energy of biogas in a CHP plant into heat and electricity. Therefore, the output side of exergy balance consists of: exergy of electric energy, exergy of heat in the form of hot exhaust, chemical exergy of digested sludge and loss of exergy related to the irreversibility of conversion processes. Due to the purpose of the analysis, the chemical exergy of digested sludge has not been calculated.

The exergy of electricity is equal to the amount of this energy, whereas the exergy of hot exhaust gases can be calculated from the formula: 


$$
E x_{h g}=\left(1-\frac{T_{0}}{T}\right) \cdot Q
$$

where: $\mathrm{T}$ - heat source temperature.

The above dependence takes into account the unavoidable irreversible energy loss associated with the conversion of heat into useful work in the ideal Carnot engine.

\section{Results}

\subsection{Variant without cavitation preprocessing of sewage sludge}

Chemical exergy of sludge on dry basis calculated from dependence (4) is $16.55 \mathrm{MJ} / \mathrm{kg}$, and from the dependence (5) it is $16.97 \mathrm{MJ} / \mathrm{kg}$. The difference in the estimated exergy between the two models for the parameters of the analyzed sewage sludge (Table 3 ) is less than $2.5 \%$. A mean value of $16.76 \mathrm{MJ} / \mathrm{kg}$ was used for further calculations.

For the assumed moisture content of sewage sludge $(80.12 \%)$, the value of chemical exergy of raw sludge at the entrance to the studying system calculated form (6) is $3.37 \mathrm{MJ} / \mathrm{kg}$, which means that after taking into account the assumed capacity of wastewater treatment plant, the exergy flow at the system entry is $8.425 \mathrm{MW}$.

For the analyzed process the magnitude of produced methane calculated form (7) is $22.95 \mathrm{~m}_{\mathrm{n}}{ }^{3} \mathrm{CH}_{4} / \mathrm{m}_{\mathrm{sl}}{ }^{3}$. Adding to the obtained methane the remaining gases contained in biogas, concentration of which is on average $35 \%\left(\right.$ mainly $\left.\mathrm{CO}_{2}\right)$ and taking into account the density of biogas under normal conditions $\left(1.15 \mathrm{~kg} / \mathrm{m}_{\mathrm{n}}{ }^{3}\right)$ [31], mass production of biogas at $484 \mathrm{~kg} / \mathrm{h}$ is achieved.

For standard chemical exergy of substances included in biogas, provided by Szargut et al. [26] (Table 1), the calculated specific exergy of their mixture according to (8) is 21.136 $\mathrm{MJ} / \mathrm{kg}$, so the exergy of the biogas stream produced in the analyzed sewage treatment plant is $2.842 \mathrm{MW}$.

In order to calculate the exergy of output streams, the energy stream contained in the produced biogas must be known. For methane higher heating value of $55.51 \mathrm{MJ} / \mathrm{kg}[10]$ and the previous assumptions, it equals 3.012 MW. Then, for the assumed electricity generation in CHP plant, exergy of electric energy is $0.896 \mathrm{MW}$ and exergy of hot gas stream calculated form (9) is $0.428 \mathrm{MW}$.

Obtained results are presented diagrammatically in fig. 2 . The overall exergy efficiency of the system without cavitation preprocessing of sewage sludge equals $15,7 \%$.

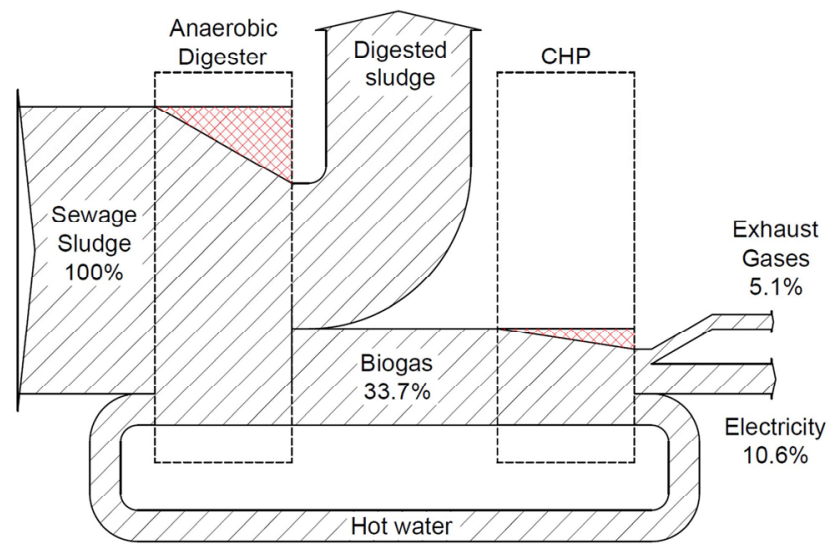

Fig. 2. Grassmann diagram of the treatment of sewage sludge without cavitation pretreatment. 


\subsection{Variant with cavitation preprocessing of sewage sludge}

Cavitation can be induced in various ways. So far, for the purpose of sewage sludge treatment, acoustic cavitation has been studied most often, however, it is proved to be less energy efficient than hydrodynamic cavitation [23], [32]. The use of cavitation pretreatment of sludge before the anaerobic digestion process allows to increase the biogas yield by $40 \%$, which means that the efficiency of the anaerobic digestion process may increase from $45 \%$ to $63 \%[7,9]$.

For the second analyzed variant of the system, with cavitation processing of sewage sludge, the exergy of sludge at the entrance to the system remains unchanged and amounts to $8.425 \mathrm{MW}$. The exergy of the obtained biogas stream increases to $3.979 \mathrm{MW}$, therefore, the exergy of electric energy and hot gas stream increases to $1.255 \mathrm{MW}$ and $0.599 \mathrm{MW}$, respectively. It means that overall exergy efficiency of the system, with cavitation preprocessing of sewage equals, increases to $22,0 \%$ (fig. 3 ).

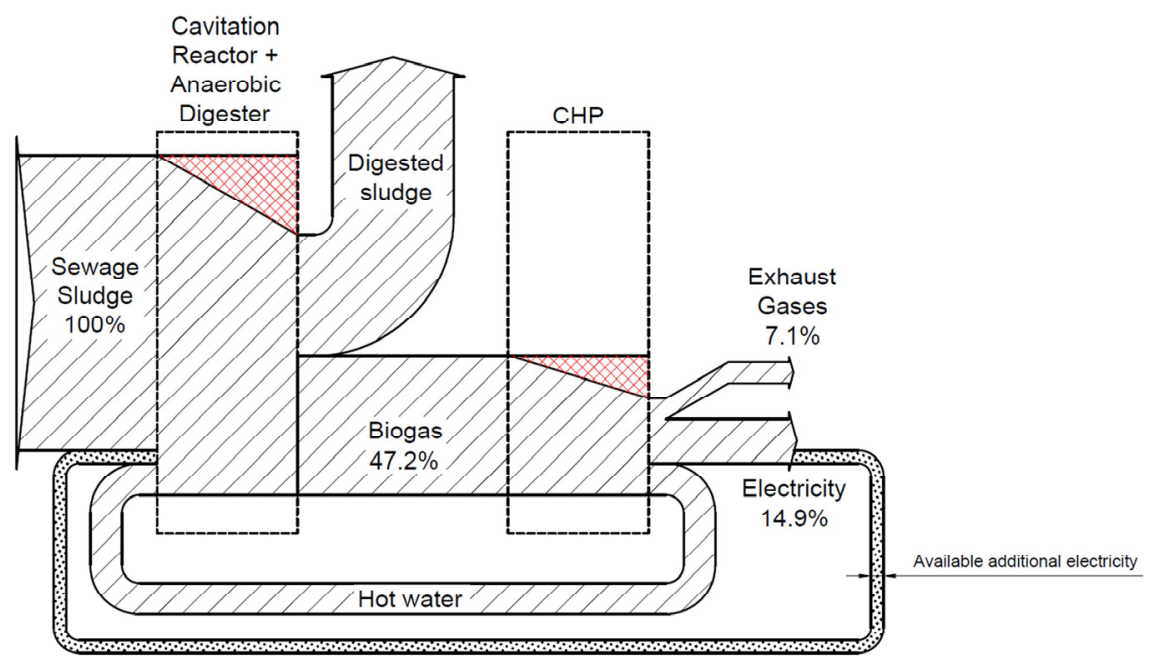

Fig. 3. Grassmann diagram of the treatment of sewage sludge without cavitation pretreatment.

\section{Discussion}

The results of the analysis are related to the specific system for which the average values of numerical parameters describing the amount and properties of sewage sludge were taken [11], [12], [14], [21], [27], [33]. Thus, the results of the analysis present a general assessment of the modified method of sewage sludge treatment, however, these may not be the same for a system with other parameters and sewage sludge with different properties than those assumed in the analysis presented in the article. A large discrepancy in these properties is presented, for example, by the higher heating value (HHV) parameter, which according to Syed-Hassan [34] for sewage sludge ranges from 11.10 to $22.10 \mathrm{MJ} / \mathrm{kg}$ (based on 32 values reported in 18 literatures), and its average value is $16.05 \mathrm{MJ} / \mathrm{kg}$.

Exergy, in the form of electric energy and hot exhaust gases, has increased as a result of cavitation pretreatment of sewage sludge before anaerobic digestion process, by $0.359 \mathrm{MW}$ and $0.1171 \mathrm{MW}$, respectively. This means that the exergy efficiency of the studied subsystem (calculated from Eq. 3) increased from almost $16 \%$ to $22 \%$. The profit in the form of electricity is particularly valuable, which justifies the use of cavitation pretreatment, insofar as the electricity consumption of the application of cavitation will be 
lower than the profit, especially since this pretreatment brings additional benefits in the form of decreasing amount of sludge to manage and reducing their toxicity.

The largest loss of exergy equaling as much as $52,8 \%$ of the initial chemical exergy of sewage sludge occurs at the stage of the anaerobic digestion process. Reduction of this loss of exergy may be potentially achieved by the use of digested sludge for further energy production in the processes of their thermal processing (pyrolysis, gasification, incineration).

\section{Conclusion}

Exergy analyses of two sludge treatment systems (with and without application of cavitation phenomenon) have been undertaken, using the same waste water parameters and CHP plant efficiency data, as an effort to compare plant performance and to assess the appropriateness of cavitation pretreatment as a potential method that may increase exergy recovery from sludge.

Obtained results of exergy analyses showed a significant decrease in the rate of exergy destruction within the system with cavitation pretreatment of sludge, thus the development of cavitation pretreatment methods, and their wider application in waste water treatment plants is potentially very beneficial.

\section{References}

1. N. Descoins, S. Deleris, R. Lestienne, E. Trouvé, F. Maréchal, Energy, 41, no. 1, 153-164 (2012)

2. M. Anjum, N. H. Al-Makishah, and M. A. Barakat, Process Saf. Environ. Prot., 102, 615-632 (2016)

3. J. Pyssa, Nowocz. Gospod. Odpad., 4(7), 2014.

4. P. Tomach, Przem. Chem., 96, no. 9, 1893-1897 (2017)

5. T. Turlej, 17th Int. Multidiscip. Sci. geoconference Ecol. Econ. Educ. Legis. Conf. Proc. Ecol. Environ. Prot., 17, no. 51, 627-634 (2017)

6. A. Abuşoğlu, E. Özahi, A. İ. Kutlar, S. Demir, Int. J. Hydrogen Energy, 42, no. 16, 10986-10996 (2017)

7. J. Ozonek, (Application of hydrodynamic cavitation in environmental engineering. London: CRC Press, 2012)

8. Q. Wang et al., Sci. Total Environ., 587-588, 510-521 (2017)

9. A. Martínez J. Uche, Energy, 35, no. 1, 77-84 (2009)

10. M. J. Moran and H. N. Shapiro, (Fundamentals of Engineering Thermodynamics, 5th ed., 181, no. 4615. West Sussex: John Wiley \& Sons Ltd, 2006)

11. M. Atienza-Martínez, J. Ábrego, J. F. Mastral, J. Ceamanos, G. Gea, Energy, 144, 723-735 (2018)

12. K. J. Ptasinski, C. Hamelinck, P. J. a. M. Kerkhof, Energy Convers. Manag., 43, no. 9-12, 1445-1457 (2002)

13. M. V. Rocco, A. Di Lucchio, E. Colombo, Appl. Energy, 194, 832-844 (2017)

14. S. Karki, J. Poudel, S. Oh, Appl. Sci., 8, no. 2, 183 (2018)

15. S. Karki, J. Poudel, S. C. Oh, Appl. Sci., 7, no. 11, 1189 (2017)

16. A. Colmenar-Santos, G. Zarzuelo-Puch, D. Borge-Diez, C. García-Diéguez, Renew. Energy, 88, 171-184, Apr. (2016)

17. L. Fitzsimons et al., J. Clean. Prod., 131, 387-398, Sep. (2016) 
18. N. F. Tumen Ozdil, A. Tantekin, Renew. Energy, 97, 390-398, Nov. (2016)

19. M. Gągol, A. Przyjazny, G. Boczkaj, Chem. Eng. J., 338, no. November 2017, 599-627 (2018)

20. G. Zhen, X. Lu, H. Kato, Y. Zhao, Y. Y. Li, Renew. Sustain. Energy Rev., 69, no. March 2016, 559-577 (2017)

21. R. Cano, S. I. Pérez-Elvira, F. Fdz-Polanco, Appl. Energy, 149, 176-185 (2015)

22. S. Różycki, (Research into the liquid ring pump as a reactor in which the process of biomass liquefaction occurs, Kraków: Katedra Systemów Energetycznych i Urządzeń Ochrony Środowiska. Wydział Inżynierii Mechanicznej i Robotyki AGH, 2016)

23. S. Rózycki, W. R. Kowalski, Przem. Chem., 96, no. 8 (2017)

24. J. Szargut, (Termodynamika techniczna, VII. Gliwice: Wydawnictwo Politechniki Śląskiej, 2013)

25. Krzysztof J. Ptasinski, (Efficiency of Biomass Energy: An Exergy Approach to Biofuels, Power, and Biorefineries. New Jersey: John Wiley \& Sons, 2016)

26. J. Szargut, D. R. Morris, and F. R. Steward, (Exergy analysis of thermal, chemical, and metallurgical processes. Berlin: Springer-Verlag, 1988)

27. R. Ślizowski, K. Chmielewski, Infrastrukt. I Ekol. Teren. Wiej., no. 2, 195-204 (2008)

28. G. Song, L. Shen, J. Xiao, Ind. Eng. Chem. Res., no. 50, 9758-9766 (2011)

29. D. R. Griffith, R. T. Barnes, and P. A. Raymond, Environ. Sci. Technol., 43 (15), 5647-5651 (2009)

30. H. Qian et al., Energy, 131, 251-258 (2017)

31. P. J. Jørgensen, (Biogas - green energy, 2nd ed. Faculty of Agricultural Sciences, Aarhus University, 2009)

32. A. G. Chakinala, P. R. Gogate, A. E. Burgess, D. H. Bremner, Chem. Eng. J., 152, no. 2-3, 498-502 (2009)

33. P. Warzecha, B. Hilger, 17th Int. Multidiscip. Sci. geoconference Conf. proceedings. Water Resour. For. Mar. Ocean Ecosyst., 17, no. 33, 119-126, (2017)

34. S. S. A. Syed-Hassan, Y. Wang, S. Hu, S. Su, and J. Xiang, Renew. Sustain. Energy Rev., 80, no. January, 888-913 (2017) 